\title{
ATIVIDADES DE MODELAGEM MATEMÁTICA: QUE SENTIDO OS ALUNOS PODEM LHE ATRIBUIR?
}

\author{
Modelling Mathematics activities: \\ what sense do students atribute to them?
}

\author{
Lourdes Maria Werle de Almeida \\ Dirceu dos Santos Brito ${ }^{2}$
}

\begin{abstract}
Resumo: Neste trabalho, abordamos a questão da atribuição de sentido às situações de ensino e aprendizagem e buscamos uma alternativa que permita ao aluno perceber a importância da matemática escolar. É com esta perspectiva que introduzimos as atividades de Modelagem Matemática e associamos o seu desenvolvimento em sala de aula com aspectos da Teoria da Atividade de Leontiev. O que o trabalho procura colocar é que duas idéias parecem convergir: por um lado, atribuir sentido e construir significados em Matemática demanda situaçōes de ensino e aprendizagem que induzam relaçōes entre a Matemática e a vida dos alunos; por outro lado, as atividades de Modelagem Matemática podem favorecer a aproximação da Matemática escolar com problemas extra-escolares vivenciados pelos alunos. Ao desenvolver uma proposta de atividades de Modelagem Matemática com alunos do Ensino Médio, a partir da análise das informaçōes que coletamos, identificamos três condições que podem favorecer a atribuição de sentido e significado numa atividade de modelagem, levando em consideração as relações estabelecidas. A primeira condição refere-se a casos em que os alunos enfrentam um problema que tem para eles importância subjetiva, ou seja, quando o problema em estudo é de fato um problema para eles. A segunda condição refere-se a casos em que ocorre engajamento crítico e transferência de aprendizagem de uma situação de modelagem para outras situações vivenciadas pelos alunos. A terceira condição dáse quando os alunos procuram tornar relevante o uso da Matemática na abordagem de um problema.
\end{abstract}

Palavras-chave: Educação Matemática. Modelagem Matemática. atribuição de sentido.

Abstract: In this article, we approach the subject of the sense attribution to teaching and learning situations and we look for an alternative that allows the student to notice the importance of mathematics. It is with this perspective that we introduce mathematical modeling activities and we associate the students' development in classroom with aspects of the Leontiev Activity Theory. Two ideas seem to converge. On one side, to attribute sense and to build meanings in mathematics teaching and learning situations, it is necessary to approach situations that can establish relationships between the Mathematics and the students' life. On the other hand, mathematical modelling activities can connect the classroom's mathematics with the problems of the community to which the students belong. When we developed a proposal for mathematical modeling activities with High School students, starting from the analysis of the information that we collected, we identified three conditions that can show the sense attribution and meaning in a modelling activity, taking into account the established relationships. The first condition refers to cases where the students face a problem that has for them subjective importance, in other words, when the problem is in fact a problem for them. The second condition refers to cases of critical engagement and transfer of learning of a modelling situation for other situations lived by the students. The third condition occurs when the students try to make relevant the use of the mathematics in the approach to a problem.

Keywords: Mathematics Education. Mathematics modeling. sense attribution.

\footnotetext{
${ }^{1}$ Professora Doutora do Programa de Mestrado em Ensino de Ciências e Educação Matemática - UEL - Paraná. E-mail: lourdes@uel.br

${ }^{2}$ Professor Mestre da Faculdade de Apucarana - FAP. E-mail: dirceumestrado@yahoo.com.br
} 
Almeida, L. M. W.; Brito, D. S.

\section{Introdução}

Em boa parte do mundo, as aulas de Matemática ocupam elevado percentual da carga horária de aulas dos estudantes. Isto parece acenar que se atribui um papel importante para a Matemática na educação. No entanto, ao lado dessa importância aparece o problema do baixo rendimento e desinteresse crescente dos alunos por essa disciplina. Essa situação, já identificada por diversos autores, nos parece conflitante e merecedora de investigação.

Alguns autores (FIORENTINI, 1995; MIGUEL, 1995) associam a esta situação o que chamam de "estilo de prática educativa". Segundo eles, se este estilo não fortalece, ou extermina, consciente ou inconscientemente, os vínculos da Matemática com a realidade, esta problemática tende a se estabilizar cada vez mais.

Para Davis e Hersh (1998), cortar vínculos e relaçôes da Matemática com a realidade é uma forma de eliminar o sentido e o significado do conhecimento matemático, uma vez que, para os autores, o sentido da Matemática inclui estas relaçôes: "A Matemática provém da conexão da mente com o mundo externo e tal conexão simultaneamente cria a Matemática e transforma nossas percepçōes do mundo externo e estas criam então novas conexōes"(p. 293).

Chevallard (2001) também associa as dificuldades encontradas no âmbito da Matemática escolar à falta de visibilidade social das atividades matemáticas e à natureza das atividades desenvolvidas nas salas de aula. Para o autor, "Os problemas escolares tendem a ser apresentados, efetivamente, como enunciados perfeitamente elaborados, cujos textos costumam esconder a problemática que lhes deu origem. Isso acontece a tal ponto que poderíamos falar de um autêntico "desaparecimento" das questôes ou das tarefas reais que originaram as obras matemáticas na escola" (p. 130).

Assim, se os alunos não conseguem "entrar" na disciplina Matemática é porque não conseguem identificar os principais tipos de problemas que lhe dão sua razão de ser, ficando limitados à aquisição de um domínio formal de técnicas, algoritmos ou a utilização de ferramentas computacionais.

Fazer com que o aluno perceba a "razão de ser" da Matemática nos remete a pensar em motivos e necessidades do aluno para se envolver com os problemas com os quais se defronta nas aulas de Matemática. Desta forma, neste trabalho, abordamos a Teoria da Atividade de Leontiev. Segundo Leontiev (1978), toda a atividade é dirigida por um motivo e atende à necessidades do sujeito. Daí decorre a significação que permite ao sujeito atribuir sentido à atividade que está desenvolvendo.

Incorporar as noções de sentido e significado às situações de ensino e aprendizagem da Matemática parece implicar uma questão básica: como ensinar e aprender Matemática, de modo que se torne importante para os alunos? Todavia, transformar questōes desse tipo em "estilos de prática educativa" pode não ser uma tarefa muito fácil.

Assim, neste trabalho buscamos uma alternativa que contribua para a luta contra as açôes destituídas de sentido na sala de aula e que permita ao aluno perceber a importância da Matemática escolar. É com esta perspectiva que introduzimos as atividades de Modelagem Matemática e associamos o seu desenvolvimento em sala de aula com aspectos da atividade como proposta por Leontiev. 
Atividades de Modelagem Matemática: que sentido os alunos podem lhe atribuir?

O que o trabalho procura colocar é que duas idéias parecem convergir: por um lado, atribuir sentido e construir significados em Matemática demanda situações de ensino e aprendizagem que induzam relaçōes entre a Matemática e a vida dos alunos; por outro lado, as atividades de Modelagem Matemática podem favorecer a aproximação da Matemática escolar com problemas extra-escolares vivenciados pelos alunos.

Deste modo, inicialmente abordamos a Teoria da Atividade e apresentamos uma noção de sentido e significado nesta teoria, bem como nas atividades de ensino e aprendizagem. A seguir, apresentamos a Modelagem Matemática como alternativa pedagógica e estabelecemos uma relação das atividades de modelagem desenvolvidas em sala de aula, com aspectos das atividades propostas por Leontiev. Finalmente, descrevemos uma experiência realizada com alunos do Ensino Médio, na qual discutimos algumas atividades de modelagem desenvolvidas. A partir da análise das informaçôes que obtivemos durante o desenvolvimento destas atividades, identificamos condições que podem favorecer a atribuição de sentido e significado numa atividade de modelagem, levando em consideração relações estabelecidas pelos alunos.

\section{Sobre a Teoria da Atividade}

A Teoria da Atividade teve suas origens nas idéias do russo Lev Semyonovitch Vigotsky (1896-1934), que, a partir de 1920, procurava explicar o desenvolvimento do indivíduo a partir de seu relacionamento social. Alexei Leontiev (1904-1979) foi um de seus principais colaboradores e seguidores e sua teoria representa um desdobramento das idéias básicas de Vigotsky.

Segundo Oliveira (2001), para Leontiev as atividades humanas são consideradas formas de relação do homem com o mundo e são dirigidas por motivos, por fins a serem alcançados, de modo que o homem se orienta por objetivos, agindo de forma intencional, por meio de ações planejadas.

O conceito de atividade não se refere apenas a ações físicas desenvolvidas por um indivíduo, mas também a ações psíquicas conscientemente controladas, como a memorização ativa, o pensamento, o comportamento intencional.

Deste modo, a atividade humana envolve açōes externas e internas. As externas, manifestadas por movimentos do corpo, são mediadas, em geral, por instrumentos e ferramentas. Nas açóes internas, por sua vez, o homem opera com imagens mentais ou instrumentos simbólicos, como a linguagem, os códigos, a matemática etc.

Leontiev (1978), ao analisar a estrutura da atividade humana, distingue três níveis de funcionamento: a atividade propriamente dita, as açōes e as operaçôes. Enquanto uma atividade (como um todo) é orientada por um motivo, as ações são orientadas por metas e as operações referem-se ao aspecto prático da realização dessas ações e envolvem condições e procedimentos. Nesse contexto, a atividade humana pode ser percebida como uma forma de relação homem-mundo, que envolve finalidades conscientes, e a atuação cooperativa é realizada por meio de açôes dirigidas por metas e desempenhada, em geral, por vários indivíduos. O resultado da atividade satisfaz a necessidades do grupo mas, também proporciona satisfação para cada indivíduo, em particular. 
Neste sentido, a noção de atividade inclui um sujeito, um resultado a ser alcançado, uma comunidade e as mediaçôes possíveis entre eles. Assim, a atividade pode ser tomada como uma unidade de análise para a compreensão de processos psicológicos, porque inclui o indivíduo e seu ambiente culturalmente definido.

\section{A noção de sentido e significado na Teoria da Atividade}

Segundo Charlot (2001), a atividade possui uma dinâmica interna que supõe uma relação com o mundo, na qual o sujeito encontra metas desejáveis, meios de ação e outros recursos que não ele mesmo. É a relação consciente entre os meios de ação e as metas desejáveis que faz com que o sujeito se mobilize em torno da atividade. Para Leontiev, o que ocupa um lugar central na mobilização de um sujeito numa atividade é a questão da significação. Para o autor, dois componentes são essenciais no processo de significação: o "significado" propriamente dito e o "sentido".

O significado refere-se ao sistema de relações objetivas que se forma no processo de desenvolvimento de uma expressão. Ele constitui um núcleo relativamente estável de compreensão que é compartilhado por todas as pessoas.

O sentido, por sua vez, refere-se ao significado da palavra para cada indivíduo, e incorpora relações que dizem respeito ao contexto de uso da palavra e a vivências afetivas do indivíduo. Assim o sentido é produzido por relaçôes. Esse sentido é o que a atividade assume para um sujeito e que o mobiliza para essa atividade. Segundo Leontiev (1978), "(...) o sentido é antes de mais nada uma relação que se cria na vida (...) O sentido consciente é criado pela relação que se reflete no cérebro do homem, entre aquilo que o incita a agir e aquilo para o qual a sua ação se orienta como resultado imediato. Por outras palavras, o sentido consciente traduz a relação do motivo ao fim" (p. 103).

A mobilização de uma pessoa em relação a uma atividade supõe, portanto, que essa pessoa tem a possibilidade de refletir sobre a relação que existe entre o motivo e o objetivo da atividade e os meios de ação empregados na sua realização.

\section{O sentido nas atividades de ensino e aprendizagem}

$\mathrm{Na}$ sala de aula, os alunos interagem entre si e com o professor de maneiras diferentes. Resolução de exercícios, investigações, relatórios orais ou escritos, jogos, discussões, são exemplos de práticas realizadas em sala de aula. Em geral, essas práticas são chamadas de atividades. Podemos distinguir, no entanto, nessas práticas, as que se enquadram na noção de atividade que consideramos neste trabalho e aquelas se seriam tarefas desenvolvidas pelos alunos.

Para abordar uma atividade de ensino e aprendizagem, consideramos a caracterização apresentada por Ponte (1995, apud MENDES, 2001):

Atividade tem um sentido mais amplo e pode incluir a execução de numerosas tarefas. Mais importante, a atividade, que pode ser física ou mental (psíquica), diz respeito essencialmente ao aluno, referindo-se àquilo que ele faz num determinado contexto. A tarefa representa apenas o objetivo de cada uma das ações em que a atividade se desdobra e é algo basicamente exterior ao aluno (embora possa ser 
Atividades de Modelagem Matemática: que sentido os alunos podem lhe atribuir?

decidido por ele). Na verdade, as tarefas são muitas vezes propostas pelo professor. Mas, uma vez propostas, têm de ser interpretadas pelo aluno e podem dar origem a atividades muito diversas (ou nenhuma atividade). (p. 36)

A noção de atividade envolve, portanto, tudo o que o aluno faz e o modo como se envolve nas situaçóes apresentadas na sala de aula. Uma tarefa de ensino e aprendizagem pode tornar-se uma atividade quando o aluno se envolve nessa tarefa e estabelece relações dentro de um "sistema mais vasto das relaçóes da sociedade, e portanto, tem uma natureza eminentemente social" (MENDES, 2001). Assim, uma tarefa de ensino e aprendizagem pode tornar-se uma atividade quando tem sentido para o aluno, quando o aluno insere suas açóes num sistema mais amplo de relações sociais e busca, por meio dessas ações, atingir um alvo desejável.

Chegando nesse ponto, podemos pensar sobre a origem do "sentido" que os alunos atribuem à sua participação em determinadas atividades. Acredita-se que a atribuição de sentido não depende exclusivamente do aluno, mas também da especificidade da atividade da qual está participando. Caberia perguntar: a atribuição de sentido a uma determinada situação didática, caracterizada aqui como atividade, depende de que fatores?

Solé (1999) aponta três fatores: em primeiro lugar, é preciso que o aluno conheça a finalidade da atividade que vai realizar, seus objetivos e condições de realização, a fim de que possa construir representaçôes favoráveis sobre ela; em segundo lugar, a atividade parecerá mais atraente ao aluno se ela preencher alguma necessidade sua; essa necessidade pode funcionar então como "motor" da ação; é preciso lembrar ainda que a necessidade pode depender da situação de ensino-aprendizagem proposta, ou seja, da natureza da atividade, do conteúdo envolvido e principalmente da forma como o professor a está propondo; finalmente, segundo a autora, a atribuição de sentido depende também das representações que o aluno forma de si mesmo enquanto participa de uma atividade, ou seja, depende de seu autoconceito acadêmico.

Neste trabalho, estamos interessados em investigar o sentido que os alunos atribuem a atividades de Modelagem Matemática desenvolvidas durante suas aulas de Matemática.

\section{Modelagem Matemática na Educação Matemática}

\section{O que é Modelagem Matemática}

A Modelagem Matemática tem sido apontada por diversos educadores matemáticos como uma alternativa pedagógica que visa relacionar Matemática escolar com questôes extra-matemáticas de interesse dos alunos, configurando uma atividade que se desenvolve segundo um esquema - um ciclo de modelagem - na qual a escolha do problema a ser investigado tem a participação direta dos sujeitos envolvidos. Assim, entendemos a Modelagem Matemática, como uma abordagem, por meio da Matemática, de um problema não essencialmente matemático.

São muitos os pesquisadores e educadores matemáticos que defendem a incorporação de atividades de Modelagem Matemática nas aulas de Matemática. Uma hipótese subjacente à proposta de modelagem na Educação Matemática é que a abordagem de questôes reais, oriundas do âmbito de interesses dos alunos, pode motivar e apoiar a aquisição e compreensão de métodos e conteúdos da matemática escolar. 
Argumentações favoráveis à utilização da Modelagem Matemática como estratégia de ensino e aprendizagem podem ser encontradas nos estudos de vários autores, como Blum e Niss, 1991; D'ambrosio, 2001; Barbosa, 2001; Bassanezzi, 2002; Almeida e Ferruzzi et al., 2002; Almeida e Dias, 2003; Borssoi e Almeida, 2004; Almeida e Dias, 2004; Borssoi, 2004, entre outros. Esses argumentos aparecem relacionados, por um lado com a motivação que as atividades podem proporcionar aos alunos e com a aplicabilidade da Matemática. Por outro lado, em um sentido mais amplo, aparecem aspectos extra-matemáticos, vinculados à competência crítica e reflexiva dos alunos.

Diversas experiências de Modelagem Matemática têm sido conduzidas em sala de aula, tanto no Brasil quanto no exterior. Nessas experiências, o encaminhamento das atividades varia, muitas vezes, em função da necessidade de se atender às exigências impostas pelo contexto escolar e também de acordo com as concepçôes sobre o papel da modelagem no currículo. Uma forma usual de conduzir uma atividade de modelagem em sala de aula consiste em dividir os alunos em grupos, que devem eleger temas de interesse para serem investigados com o uso da Matemática, contando com a orientação do professor. Segundo Bassanezzi (2002), nesse caso, a Matemática pode surgir à medida que se vai lidando com os problemas, ou seja, "o programa vai sendo desenvolvido à medida que o problema exige novos conceitos".

$\mathrm{O}$ que se pode observar é que um dos pressupostos subjacentes à proposta de Modelagem Matemática é de que o engajamento do aluno numa modelagem possibilita a compreensão não só de aspectos teóricos e técnicos da Matemática, mas também permite identificar as questôes que lhe dão sua razão de ser. Esse argumento se apóia no fato de que o processo de modelagem não envolve apenas conhecimento matemático. No processo de modelagem destacam-se basicamente três tipos de conhecimento: o conhecimento matemático, o conhecimento tecnológico e o conhecimento reflexivo (SKOVSMOSE, 2001).

O conhecimento matemático se refere, à competência normalmente entendida como um conjunto de habilidades matemáticas, incluindo-se as competências na reprodução de teoremas e provas, bem como ao domínio de uma variedade de algoritmos. O conhecimento tecnológico refere-se às habilidades em aplicar a matemática e às competências na construção de modelos. O conhecimento reflexivo, por sua vez, refere-se à competência de refletir sobre o uso da matemática e avaliá-lo. Estas reflexões têm a ver com avaliações de conseqüências que este uso pode trazer para a sociedade.

Uma das principais razóes apontadas para se fazer modelagem na sala de aula é a necessidade de tornar visível aos estudantes o papel da matemática fora da sala de aula. Diversas decisōes são tomadas na sociedade com base em modelos matemáticos. A presença da matemática, como forte aliada do desenvolvimento tecnológico, tem afetado direta e indiretamente a vida das pessoas. Skovsmose (2001), apoiado em Davis e Hersh, (1998), afirma que a matemática está formatando a sociedade. Esse poder de formatação se relaciona com o uso de modelos matemáticos para descrever, predizer e prescrever situaçôes importantes da vida social.

A Modelagem Matemática pode criar condições para discutir e questionar este poder de formatação da matemática, tornando visível a importância que a matemática tem para a sociedade. Tornar visível esta importância, requer, segundo Niss (1992), que se realize modelagem com casos autênticos de aplicações de matemática. Ser um caso autêntico, nesse 
Atividades de Modelagem Matemática: que sentido os alunos podem lhe atribuir?

caso, significa pertencer a uma disciplina ou atividade existente fora da matemática, compreendendo objetos, fenômenos, questões e problemas que têm um interesse genuíno numa perspectiva extramatemática.

$\mathrm{Na}$ tentativa de buscar um entendimento sobre o sentido que os alunos atribuem às atividades de Modelagem Matemática nas aulas, vamos caracterizá-las como atividades segundo a noção de atividade de ensino e aprendizagem que abordamos neste artigo.

\section{Modelagem Matemática como uma atividade da aula de Matemática}

Buscamos, neste momento, estabelecer uma relação entre a Modelagem Matemática e os conceitos de atividade e sentido que apresentamos nas seçôes anteriores.

Com esta finalidade, levamos em consideração que a caracterização de atividade de ensino e aprendizagem defendida por Ponte (1995, apud MENDES, 2001) e que apresentamos neste texto, atribui dois elementos básicos a uma atividade: a função orientadora das ações, em que se considera uma linha invisível que define o trajeto que conduz ao saber; a existência de um motivo para a realização da atividade.

Neste contexto, uma Modelagem Matemática torna-se uma atividade, na perspectiva da Teoria da Atividade, quando os alunos se envolvem em um conjunto de ações coordenadas e percebem "a linha invisível" que orienta estas ações e quando assume uma importância subjetiva para os alunos, ou seja, a atividade tem um motivo.

Compreender a Modelagem Matemática como atividade na perspectiva da Teoria de Atividade de Leontiev, implica a caracterização das relações que os alunos estabelecem entre o objetivo de suas ações e o motivo que sustenta sua atividade. Significa pensar nos elementos que conferem sentido à atividade de Modelagem Matemática.

A compreensão da atividade de modelagem na Educação Matemática é apresentada em termos de processo de construção de um modelo matemático, que se presta a descrever determinada problemática e lhe sugerir soluções e atua como uma "função orientadora das ações". Este processo envolve um conjunto de ações desenvolvidas pelos alunos - experimentação, seleção de variáveis, formulação de hipóteses, simplificações, resolução de problemas e validação do modelo vinculado ao contexto de uma situação não essencialmente matemática.

Os motivos que sustentam a atividade de Modelagem Matemática dos alunos podem assumir diferentes aspectos. Neste contexto, consideramos que os motivos estão ligados, por um lado, às necessidades educacionais dos alunos. Por isso, as ações que desenvolvem nas atividades de modelagem se orientam por motivos de natureza escolar e educacional e são menos ligados aos aspectos técnicos da modelagem. Por outro lado, os motivos estão associados ao problema que os alunos se propõem a resolver. Se este lhes representa um problema de fato, que lhes interessa resolver, então o motivo para a realização da atividade está estabelecido.

Uma vez estabelecida a caracterização da Modelagem Matemática como atividade segundo Leontiev, descrevemos como objetivo deste trabalho investigar as relações que os alunos estabelecem entre as suas ações e o motivo que as sustenta. Nossa unidade de observação e análise é, portanto, a atuação dos alunos quando da realização de atividades de Modelagem 
Matemática nas aulas de Matemática. Queremos analisar as relaçôes que estes alunos estabelecem entre a situação-problema em estudo, a matemática envolvida no estudo desta situação e o próprio aluno. Com isso, procuramos evidenciar o maior ou menor grau de sentido que os alunos atribuem à Modelagem Matemática ou à Matemática, a partir do modo como estas relações são estabelecidas.

\section{Atribuição de sentido em atividades de Modelagem Matemática}

Para investigar as questôes apresentadas até o momento, planejamos e estruturamos uma proposta de ensino e aprendizagem via Modelagem Matemática. Este estudo foi realizado com duas turmas de alunos do segundo ano do Ensino Médio numa escola pública de Londrina - Paraná - Brasil. Inicialmente, exploramos com esses alunos uma Modelagem Matemática já estruturada. Em seguida, sugerimos um tema e os alunos pesquisaram e realizaram a modelagem sob nossa orientação. Finalmente, os alunos, organizados em grupos de até cinco membros, escolheram um tema e pesquisaram e elaboraram um trabalho de modelagem que foi entregue por escrito. Os trabalhos elaborados pelos grupos, a observação direta dos alunos, a aplicação de questionários e a realização de uma entrevista semi-estruturada foram os procedimentos metodológicos empregados para a coleta de informações sobre o problema em estudo.

A partir da análise das informações, identificamos três condiçōes que podem favorecer a atribuição de sentido e significado numa atividade de modelagem, levando em consideração as relações estabelecidas. A primeira condição refere-se a casos em que os alunos resolvem um problema que tem para eles importância subjetiva, ou seja, quando o problema em estudo é de fato um problema para eles. A segunda condição refere-se a casos em que ocorre engajamento crítico e transferência de aprendizagem de uma situação de modelagem para outras situações vivenciadas pelos alunos. A terceira condição dá-se quando os alunos procuram tornar relevante o uso da matemática na abordagem de um problema. Analisamos e exemplificamos a seguir cada uma dessas condições em três casos.

\section{Caso 1: A importância subjetiva do problema}

Um grupo de alunas, preocupadas com o problema de obesidade, optou por estudar o gasto de energia em diversas atividades físicas. Após pesquisas na internet, o grupo descobriu que o gasto de energia numa caminhada pode ser aumentado apenas alterando o ritmo das passadas. Essa descoberta fez com que elas definissem como problema a ser investigado a seguinte questão: como gastar o máximo de energia numa caminhada com o mínimo de esforço, apenas controlando o ritmo das passadas?

Esse grupo obteve na internet duas tabelas: uma relacionando o tempo de uma caminhada com seu gasto de energia, mantendo-se a distância constante, e outra tabela relacionando a velocidade com a distância percorrida na caminhada, mantendo-se constante a energia gasta. A resolução do problema, apresentada pelo grupo, consistiu em empregar o recurso de ajuste de curvas do programa Excel para obter funções quadráticas simulando a tendência dos dados das duas tabelas (Figuras 1 e 2). A partir das funçōes obtidas, esse grupo calculou as coordenadas dos pontos máximo e mínimo que conduzem à solução do problema, ou seja, o tempo em que se deve percorrer uma determinada distância para gastar o máximo de energia e a velocidade mínima que se deve imprimir às passadas para gastar uma determinada quantidade de energia. 
Atividades de Modelagem Matemática: que sentido os alunos podem lhe atribuir?

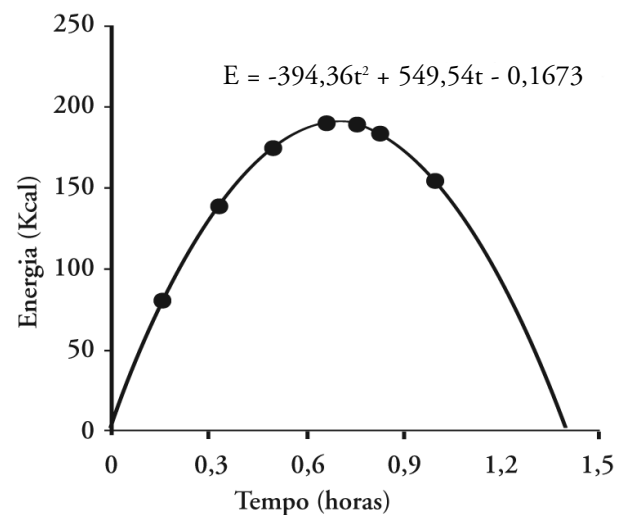

Figura 1 - Energia em função do tempo

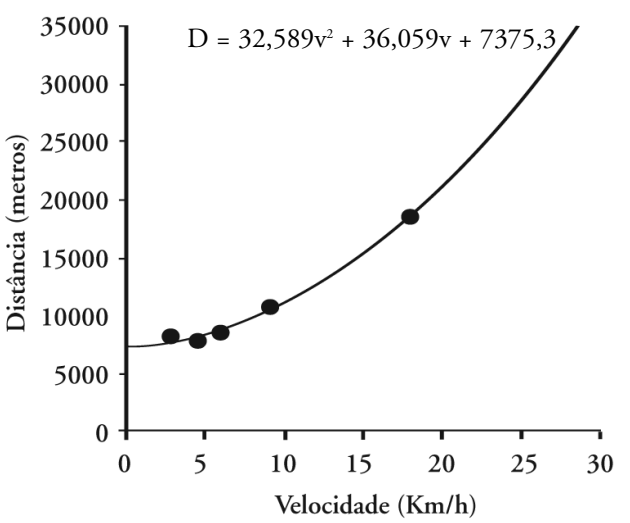

Figura 2 - Distância em função da velocidade

Desde a escolha do tema, esse grupo demonstrou grande interesse no desenvolvimento da modelagem e preocupação constante com o problema estudado. Nessa modelagem, a escolha do tema e a definição do problema investigado surgiram de uma inquietação comum no grupo, como mostram algumas de suas falas:

\section{A1: Nós fizemos um trabalho sobre ritmo da caminhada.}

A2: ... o ritmo da caminhada... porque... tipo assim... é que a gente vive fazendo regime... essas coisas aí.. só que a gente nunca faz nada certo e...

A3: É que hoje em dia as pessoas se preocupam muito com a beleza do corpo, mas não vê que também caminhar é necessário para a nossa saúde.

A2: $E$ tem gente que não sabe fazer a caminhada certo, já comeşa fazendo... tipo 40 minutos... exagera... tem gente que começa a correr e... tipo, nunca andou muito certo...

A1: Tem que ir fazendo aos poucos e ir aumentando a cada dia um pouquinho... não já comę̧ar correndo assim.

A partir do momento em que o grupo definiu o problema de estudo, percebeu que se tratava de um problema genuíno. Genuíno porque oriundo de uma situação extramatemática com certa relevância subjetiva para o grupo. Genuíno também porque, em sua resolução, o grupo pôde empregar um instrumental, no caso funçôes quadráticas, que permitiu obter uma reposta satisfatória para o problema. A escolha de funções quadráticas se deu a partir da observação do comportamento dos dados oriundos do problema - "cresce e decresce ou viceversa" - e pelo tipo de resolução que se esperava obter - "calcular o máximo e o mínimo da função". Houve, portanto, construção de significados matemáticos para esse tipo de função, o que contribuiu para que os alunos tivessem de si mesmos uma imagem positiva diante destes conceitos, percebendo que os haviam compreendido. Este parece ser um dos fatores estabelecidos por Solé, que citamos anteriormente.

Assim, a atribuição de sentido e significado nessa modelagem teria sido motivada basicamente pela natureza do problema que inquietava ou incomodava o grupo e cuja resolução pareceu, em certos aspectos, necessária aos seus membros. Não seria exagero dizer, portanto, 
que a resolução do problema poderia ter assumido um papel prescritivo para o grupo. A combinação da escolha do tema, formulação adequada do problema aliada com uma interpretação criativa de sua resolução seria, assim, uma condição fundamental para a atribuição de sentido e significado em situações de Modelagem Matemática.

Os discursos descritos insinuam que os alunos tinham motivo para realizar esta atividade e que, de certo modo, a sua realização lhes traria satisfação.

\section{Caso 2: Engajamento critico e transferência de aprendizagem}

Noutro caso, um grupo de alunos optou por fazer seu trabalho de modelagem sobre os efeitos da altitude no corpo humano. A escolha do tema não partiu do grupo, mas foi sugerida pelo professor a partir de uma reportagem informando a comemoração dos 50 anos da conquista do Monte Everest. Sabe-se que a chegada no topo do Monte Everest envolveu vários obstáculos, entre eles a dificuldade de respiração e a baixa temperatura.

Esse grupo pesquisou em livros, na internet e consultou um especialista da área de saúde para entender como a variação da tensão de oxigênio no ar afeta o corpo humano. A idéia básica desse grupo era encontrar dados numéricos que permitissem relacionar a variação da tensão de oxigênio no ar com algum efeito físico em nosso organismo, mas obteve apenas uma tabela relacionando a variação da tensão de oxigênio com o aumento da altitude.

A modelagem desenvolvida pelo grupo consistiu basicamente em ajustar uma função exponencial decrescente aos dados obtidos e relacionar numa tabela a diminuição da tensão de oxigênio com a diminuição da capacidade de respiração em termos percentuais. Esse grupo não resolveu de fato um problema. E, por isso mesmo, o modelo matemático obtido pouco acrescentou ao que já se sabia sobre os efeitos da altitude no organismo humano.

Esse trabalho de modelagem não parece ter sido motivado por um problema que o grupo realmente necessitava resolver. Mas, a partir do engajamento dos alunos na busca de diversas fontes de informação sobre o tema, o grupo pôde transferir o que aprendeu na modelagem para outras situações de seu interesse. O grupo cita, por exemplo, que essa modelagem ajudou a entender porque os times de futebol, antes de jogar em cidades de grande altitude, devem fazer rigorosa preparação física para enfrentar os problemas de aclimatação. Ou, porque aumenta acentuadamente a freqüência cardíaca e respiratória durante uma atividade esportiva nas aulas de educação física. Um aluno desse grupo relaciona, por exemplo, a importância de fazer modelagem com a possibilidade de aprender outras formas de conhecimento que não o estritamente matemático:

A1: Posso dizer que é muito importante fazer modelagem por que... é... implica muito de você pesquisar.. nós tivemos que pesquisar uma tabela para tirar da tabela essa função... e, dentro do problema resolvido, nós tivemos que achar a concentração de oxigênio de três cidades, diversas uma em cada altitude, então isso ajudou muito a nos orientar não só em Matemática mas em outros conhecimentos também. Principalmente em matemática porque nos mostrou como a matemática está relacionada com as coisas do nosso dia-a-dia mesmo, mesmo nessas coisas simples.

Outro aluno desse mesmo grupo também fala das vantagens de fazer modelagem durante as aulas de Matemática fazendo referência à possibilidade de transferir os conhecimentos aprendidos nas situações de modelagem para outras situações. 
Atividades de Modelagem Matemática: que sentido os alunos podem lhe atribuir?

A2: Bom, as vantagens.. é assim... que a partir do momento em que a gente começou a trabalhar a Modelagem Matemática, a gente pôde ver que outros cálculos do nosso cotidiano podem ser feitos, né? A gente pode pegar outros temas que estão ao nosso redor que às vezes a gente nem imagina que podem ser calculados com matemática, né? Mas a gente vendo isso... a gente pode ver indices, crescimentos, desenvolvimentos em outros temas.

Já mencionamos que essa modelagem não partiu de uma inquietação sentida no grupo, nem de um problema cuja resolução os alunos se interessavam em obter. Mas na medida em que o grupo se engajou criticamente na atividade construiu relaçóes que possibilitaram transferências de aprendizagem. Empregamos a expressão "engajamento crítico" com a mesma conotação com que Skovsmose a utiliza quando se refere a atividades de Modelagem Matemática que assumem importância subjetiva para os alunos, relacionam-se a processos importantes na sociedade e que servem de base para um engajamento político e social posterior (SKOVSMOSE, 2001).

Neste caso, o motivo que sustenta a realização da atividade parece estar associado justamente à possibilidade de aprender outras formas de conhecimento que não o estritamente matemático, e o engajamento crítico e a transferência de aprendizagem, nesse caso, teriam sido a condição para a atribuição de sentido ao que foi aprendido. Charlot refere-se a esse fenômeno de atribuição de sentido pelo engajamento numa atividade em termos de dialética entre o sentido e a eficácia da aprendizagem. "Trata-se propriamente de uma dialética e não de uma simples complementaridade: o sentido atribuído a um saber leva a envolver-se em certas atividades, a atividade posta em prática para apropriar-se de um saber contribui para produzir o sentido desse saber" (CHARLOT, 2001).

\section{Caso 3: A relevância da matemática numa modelagem}

Após tomar conhecimento de uma reportagem da revista Veja, de 11 de julho de 2003, sobre a idade biológica das pessoas, um grupo se interessou em abordar esta situação por meio da matemática. No entanto, não havia entre os componentes do grupo nenhuma idéia do que seria realmente um problema a ser investigado nesta situação. A idéia inicial era simplesmente ajustar funçōes aos dados disponibilizados na reportagem, fazer seus gráficos e nada mais.

Desse modo, era necessário que, inicialmente, o grupo formulasse um problema com as informações disponíveis na reportagem. De preferência, um problema que os inquietasse, que os intrigasse ou que achassem interessante resolver com o uso de matemática. Era preciso esclarecer que obter funções e fazer gráficos numa modelagem têm o intuito de ajudar a resolver um problema, não pode ser um fim em si mesmo. Com essa orientação, o grupo se propôs a pensar sobre o que de fato poderia ser um problema matemático naquela reportagem e que resultaria num bom trabalho de modelagem.

Mas em vez de pensar em problemas que fossem de seu interesse, o objetivo do grupo passou a ser encontrar situaçôes que justificassem o uso da matemática no estudo daquele tema. A partir de um teste proposto na reportagem, para estimar a idade real do corpo humano, ou seja, sua idade biológica, esse grupo procurou questōes que tornassem relevante a aplicação de matemática naquele tema. Um item desse teste consistia em puxar levemente a pele da parte de cima da mão relaxada e soltar. Com a ajuda de uma tabela, estimava-se 
a idade biológica a partir do tempo que a pele da mão leva para voltar à posição normal. Outro item desse teste permitia estimar a idade biológica de uma pessoa a partir da máxima distância que ela consegue ouvir outra pessoa lendo um texto num tom normal de voz.

No caso da elasticidade da pele, o grupo percebeu que a relação entre o tempo que a pele demora em voltar ao normal e a idade biológica da pessoa poderia ser aproximada com uma função afim (Figura 3). O grupo procurou justificar o uso dessa função mostrando como o fenômeno da elasticidade da pele pode ser explicado a partir das propriedades dessa função. A taxa de variação da função, por exemplo, foi relacionada com a perda da elasticidade da pele em termos percentuais.

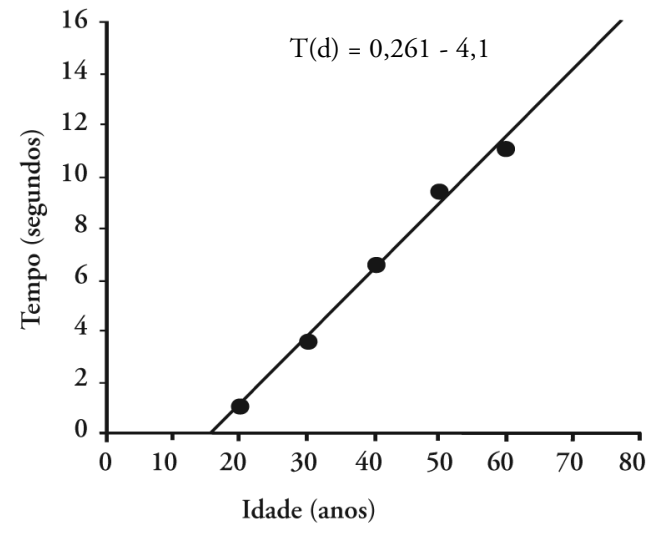

Figura 3 - Tempo em função da idade

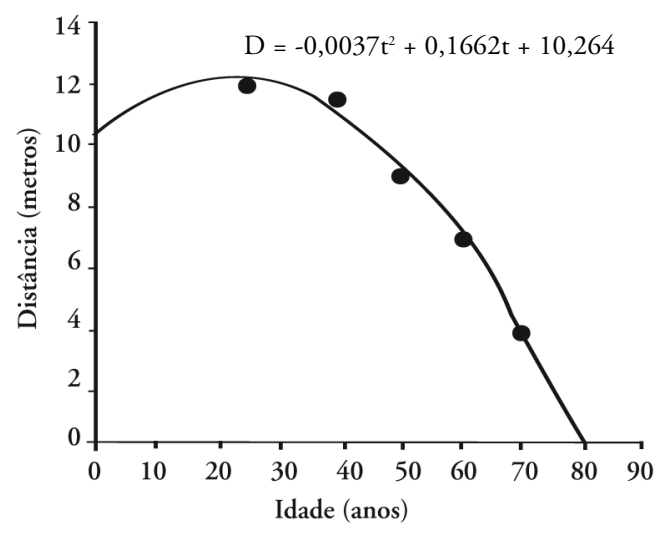

Figura 4 - Distância em função da idade

Observando a tendência dos dados, o grupo percebeu que a perda de audição em função da idade poderia ser relacionada com uma função quadrática (Figura 4). Assim, o grupo procurou tornar relevante o uso dessa função no estudo da perda de audição mostrando que como esse fenômeno pode ser interpretado à luz de uma função quadrática. O grupo explicou que o ponto em que essa função intercepta o eixo das coordenadas seria a distância máxima que permite à pessoa ouvir com clareza logo que nasce; o ponto de máximo dessa função estimaria a idade em que a pessoa ouve melhor; e o ponto em que a função intercepta o eixo das abscissas estimaria a idade em que a pessoa ficaria totalmente surda. Essas consideraçōes ficam evidenciadas em algumas falas do grupo:

A1: Nosso problema era saber conforme vai aumentando os anos da pessoa vai diminuindo audição e a elasticidade da pele diminui...

A2: A gente percebeu né, que conforme vai diminuindo a elasticidade da pele vai perdendo a audição, né? Conforme diminui a elasticidade, demora mais prá voltar, né... porque vai esticando muito e a audição vai diminuindo. O ponto máximo da função era o ponto que a gente escutava melhor... dai tinha a idade certa lá que tinha o ponto máximo que quando você ia escutar melhor... porque pequeno você não escuta muito bem, nem velho... então tem uma idade exata que você escuta melhor... achar essa idade éo problema do trabalho. 
Atividades de Modelagem Matemática: que sentido os alunos podem lhe atribuir?

O sentido que esse grupo atribuiu à realização do trabalho de modelagem parece estar pouco relacionado com o tema ou com o problema estudado. Não parece também ser oriundo de preocupações que esse grupo tinha com a questão da perda de audição e elasticidade da pele em função do envelhecimento. Nem mesmo seria oriundo da transferência de aprendizagem desse tema para outras situações relacionadas. Nesse caso, a busca do grupo em explorar criativamente aspectos matemáticos do tema escolhido teria sido o "motor" da atividade de modelagem dos alunos. Em outros termos, ao procurar tornar relevante o uso da matemática nessa modelagem, os alunos desse grupo teriam atribuído sentido e significado ao que aprenderam. O motivo dos alunos, neste caso, está associado à aplicação de conceitos da matemática. As necessidades dos alunos neste momento pareciam mesmo ser educacionais. No entanto, a satisfação em encontrar situações onde a Matemática escolar se aplica parecia também atribuir sentido à atividade.

\section{Considerações finais}

Neste trabalho, incorporamos elementos da Teoria da Atividade na investigação e análise de situaçôes de Modelagem Matemática. Acreditamos que esta teoria pode ajudar a compreender alguns aspectos do ensino e aprendizagem da Matemática, por meio de atividades de Modelagem Matemática, de uma forma mais ampla. Como bem salienta Skovsmose, a Teoria da Atividade "é um grande passo em direção a uma epistemologia dialógica, antes de tudo, enfatizando que temos de fazer alguma coisa para obter conhecimento, e fazê-lo num contexto social. A atividade não é um ato isolado" Skovsmose (2001, p. 62). O que se procura, mais especificamente, com este trabalho, é perceber que sentido os alunos atribuem às atividades de Modelagem Matemática nas aulas de Matemática.

O que se pode concluir é que, a Matemática em atividades de modelagem assume para os alunos sentido e significado que provavelmente diferem daqueles das aulas convencionais. De forma geral, ao envolver-se com atividades de modelagem os alunos estabelecem algumas relações e elas podem ajudá-los a atribuir sentidos porque "produzem intelegibilidade sobre algo... aclaram algo no mundo" (CHARLOT, 2000).

Ao trabalhar com alunos de Ensino Médio, podemos pensar que eles já possuem uma relação constituída com a Matemática e algumas atividades de ensino e aprendizagem desenvolvidas nas aulas. A atribuição de sentido em situações de modelagem pode imbricar-se, de algum modo, nesta relação.

A idéia, inicialmente colocada, de que a atribuição de sentido em matemática demanda situações de ensino e aprendizagem que induzam relações entre a Matemática e a vida dos alunos, e que, as atividades de Modelagem Matemática favorecem estas relações, parecem se confirmar na situação de estudo que descrevemos.

As três condições que identificamos para a atribuição de sentido nas atividades de Modelagem Matemática, quando incorporadas nas atividades de sala de aula podem fazer com que o conhecimento construído nestas atividades seja dinâmico, tenha vida.

Atribuir sentido a atividades de Modelagem Matemática envolve o aluno no seu contexto mais amplo. Este trabalho procura incorporar essa visão mais ampla a respeito do ensino e da aprendizagem da Matemática. 
Almeida, L. M. W.; Brito, D. S.

\section{Referências}

ALMEIDA, L. M. W.; BORSSOI, A. H. Modelagem Matemática e aprendizagem significativa: uma proposta para o estudo de equações diferenciais ordinárias. Educação Matemática Pesquisa, v. 6, n 2, p. 91-122, 2004.

.; DIAS, M. R. Um estudo sobre o uso da Modelagem Matemática como estratégia de ensino e aprendizagem. Bolema, v. 17, n. 22, p. 19-36, 2004.

- Modelagem Matemática na Licenciatura em Matemática: contribuições para o debate. In: SEMINÁRIO INTERNACIONAL DE EDUCAÇÃO MATEMÁTICA, 2., 2003, Santos. Anais... Santos, 2003. 20p.

.; BRITO, D. S. Modelagem Matemática na sala de aula: algumas implicações para o ensino e a aprendizagem da Matemática. In: CONFERÊNCIA INTERAMERICANA DE EDUCAÇÃO MATEMÁTICA, 2003a, Blumenal, Anais... Blumenal, 2003 a.

. Introdução à Modelagem Matemática. Notas de aula do curso de Mestrado em Ensino de Ciências e Educação Matemática. UEL. Londrina, PR, 2002a.

BASSANEZI, R. C. Ensino-aprendizagem com Modelagem Matemática. São Paulo: Contexto, 2002.

BLUM, W.; NISS, M. Applied mathematical problem solving, modelling, applications, and links to other subjects - state, trends and issues in mathematics instruction. Educational Studies in Mathematics, v. 22, n. 1, p. 37-68, feb, 1991.

BORSSOI, A. H.; ALMEIDA, L. M. W. O Processo de Ensino e Aprendizagem acontecendo num Ambiente de Modelagem Matemática e Tecnologias Informáticas: buscando uma aprendizagem significativa. In: ENCONTRO PARANAENSE DE EDUCAÇÃO MATEMÁTICA, 7., 2002, Foz do Iguaçu. Anais..., Foz do iguacu, 2002.

O ensino de cálculo e as atividades de modelagem matemática em ambientes informatizados. In: ENCONTRO BRASILEIRO DE ESTUDANTES DE PÓSGRADUAÇÃO EM EDUCAÇÃO MATEMÁTICA, 6., 2002, Campinas. Anais... Campinas, 2002. p. 76-81

. Aprendizagem significativa em atividades de Modelagem Matemática como estratégia de ensino. Londrina, 2003. Dissertação (Mestrado em Ensino de Ciências e Educação Matemática) - Universidade Estadual de Londrina.

BRITO, D. S.; ALMEIDA, L. M. W. Refletindo sobre "a duração do dia" por meio de uma atividade de Modelagem Matemática. - ENCONTRO PARANAENSE DE EDUCAÇÃO MATEMÁTICA, 7., 2002. Anais..., Foz do Iguaçu, 2002.

CHARLOT, B. Da Relação com o Saber: Elementos para uma teoria. Porto Alegre: Artmed Editora, 2000.

. (org.) Os Jovens e o Saber: Perspectivas mundiais. Porto Alegre: Artmed Editora, 2001. 
Atividades de Modelagem Matemática: que sentido os alunos podem lhe atribuir?

CHEVALLARD, Y. et al. Estudar Matemáticas: O elo perdido entre o ensino e a aprendizagem. Porto Alegre: Artmed Editora, 2001.

D'AMBROSIO, U. Educação para uma sociedade em transição. Campinas: Papirus, 1999.

- Etnomatemática: elo entre as tradições e a modernidade. Belo Horizonte:

Autêntica, 2001.

DAVIS, P. J.; HERSH, R. A experiência matemática. Rio de Janeiro: Francisco Alves, 1986.

FERRUZZI, E. C. A Modelagem Matemática como estratégia de ensino e aprendizagem do Cálculo Diferencial e Integral nos Cursos Superiores de Tecnologia. Florianópolis, 2003. Dissertação. (Mestrado em Engenharia de Produção e Sistemas), Universidade Federal de Santa Catarina.

.; ALMEIDA, L. M. W.; GONÇALVES, M. B. Dedução da Lei de OHM usando modelagem e investigação matemática. In: SEMINÁRIO DE INVESTIGAÇÃO EM EDUCAÇÃO MATEMÁTICA, 12., 2002. Lisboa: Associação de Professores de Matemática. Actas..., 2002, p. 333-343.

FIORENTINI, D. Alguns modos de ver e conceber a Matemática no Brasil. Zetetikê, v. 3, n. 4, 1995.

LEONTIEV, A. N. O desenvolvimento do psiquismo. Lisboa: Horizonte Universitário, 1978.

MENDES, E. J. A propósito da actividade. Educação Matemática em Revista, n. 61, p. 3639, 2001.

MIGUEL, A. A constituição do formalismo pedagógico clássico em Educação Matemática. Zetetikê, v. 3, n. 3, 1995.

NISS, M. Applications and modelling in the mathematics curriculum - state and trends. Int. J. Math. Educ. Sci. Tecnol., London, v. 18, n. 4, p. 487-505, jul/aug 1987.

- O Papel das aplicaçõos e da modelação na Matemática escolar. Educação e Matemática, n. 23, p. 1-2, 1992.

OLIVEIRA, M. K. Vikotsky, aprendizagem e desenvolvimento: um processo histórico sóciohistórico. São Paulo: Scipione, 2001.

SKOVSMOSE, D. Educação Matemática Crítica: a questão da democracia. Campinas: Papirus, 2001.

SOLÉ, I. Disponibilidade para a aprendizagem e sentido da aprendizagem. In: COLL, C. $O$ construtivismo na sala de aula. São Paulo: Ática, 1998.

Artigo recebido em fevereiro de 2005 e selecionado para publicação em setembro de 2005. 
